\title{
SETD7 regulates chondrocyte differentiation and glycolysis via the Hippo signaling pathway and HIF-1 $\alpha$
}

\author{
MAOQUAN LI ${ }^{1,2^{*}}$, JINQIU NING ${ }^{1,2^{*}}$, JIWEI WANG ${ }^{3}$, \\ QIQIAN YAN ${ }^{1,2}, \mathrm{KE} \mathrm{ZHAO}^{1,2}$ and XIAOSHI JIA ${ }^{1,2}$ \\ ${ }^{1}$ Hospital of Stomatology, Guanghua School of Stomatology, Sun Yat-sen University; \\ ${ }^{2}$ Guangdong Provincial Key Laboratory of Stomatology, Guangzhou, Guangdong 510055; \\ ${ }^{3}$ Key Laboratory of Oral Medicine, Guangzhou Institute of Oral Disease, Stomatology Hospital of \\ Guangzhou Medical University, Guangzhou, Guangdong 510140, P.R. China
}

Received June 13, 2021; Accepted August 30, 2021

DOI: $10.3892 /$ ijmm.2021.5043

\begin{abstract}
Chondrocytes are well adapted to hypoxia and produce more functional extracellular matrix in low oxygen environments in vitro. In our previous study, methyltransferase SET domain containing (SETD)7 regulated chondrocyte activity in hypoxic conditions. However, the precise association between SETD7 and chondrocyte differentiation under low oxygen partial pressure remains unclear. The association between SETD7 and chondrocyte differentiation was studied by silencing SETD7 in chondrocytes in vitro. The results showed that the silencing of SETD7 in ATDC5 cells inhibited the Hippo signaling pathway, decreased Yes-associated protein (YAP) phosphorylation and increased the levels of YAP and hypoxia inducible factor- $1 \alpha$ (HIF-1 $\alpha$ ) in the nucleus. YAP combined with HIF-1 $\alpha$ to form a complex that promoted the expression of genes involved in chondrogenic differentiation and the glycolytic pathway. Thus, SETD7 inhibited chondrocyte differentiation and glycolysis via the Hippo signaling pathway. The present study demonstrated that SETD7 was a potential molecular target that maintained the chondrocyte phenotype during cartilage tissue engineering and cartilage-associated disease.
\end{abstract}

Correspondence to: Professor Ke Zhao or Dr Xiaoshi Jia, Hospital of Stomatology, Guanghua School of Stomatology, Sun Yat-sen University, 56 Lingyuan West Road, Guangzhou, Guangdong 510055, P.R. China

E-mail: zhaoke@mail.sysu.edu.cn

E-mail: jiaxsh3@mail.sysu.edu.cn

*Contributed equally

Key words: SET domain containing 7, Yes-associated protein, hypoxia inducible factor-1 $\alpha$, Hippo, energy metabolism, differentiation

\section{Introduction}

Cartilage defects caused by congenital abnormality, trauma or inflammation in the weight bearing joint cause extensive health issues for the patient. Cartilage tissue engineering enables repair of cartilage defects, which are difficult to repair due to the lack of regenerative ability of chondrocytes $(1,2)$. Although various types of scaffold for cartilage repair have been developed, dedifferentiation of chondrocytes causes a challenge to cartilage tissue engineering $(3,4)$. With continuous monolayer expansion, chondrocytes dedifferentiate and lose phenotypical characteristics, displaying fibroblastic phenotype, thus affecting their cartilage-forming ability (5). To reconstruct cartilage tissue, it is necessary to develop a method to maintain the chondrocyte phenotype during chondrocyte amplification.

Proliferation and differentiation of chondrocytes are influenced by numerous factors, such as density of cell inoculation (6), composition of culture medium (7) and two or three-dimensional culture conditions (8). Oxygen partial pressure is another key factor affecting chondrocyte differentiation and cartilage formation (9). The oxygen partial pressure is $1-5 \%$ inside normal cartilage because of the lack of blood vessels (10). Chondrocytes produce more functional extracellular matrix in hypoxic compared with in normoxic environments (11). However, the mechanism of chondrocyte differentiation under low oxygen partial pressure remains unclear.

Differentiation of chondrocytes and cartilage formation are regulated by a variety of methylases (12). In our previous study, the lysine methyltransferase $\mathrm{Su}($ var)3-9, enhancer of zeste and trithorax (SET) domain containing 7 (SETD7) regulated apoptosis of chondrocytes at different oxygen partial pressures (13). SETD7 specifically identifies the K/R-S/T-K* amino acid sequence and transfers a methyl group to lysine residue of $\mathrm{K}^{*}$ (14). SETD7 is involved in cell cycle regulation, DNA damage response, gene transcription and cell differentiation (15). To the best of our knowledge, however, the role and mechanism of SETD7 in regulating chondrogenic differentiation have not been studied.

Hippo signaling controls organogenesis and cell differentiation (16). When Hippo signaling is activated, a series of phosphorylation events occur via mammalian STE20-like 
$\mathrm{T}$ cells (MST) and the linker for activation of $\mathrm{T}$ cells (LAT) kinases, ultimately leading to phosphorylation of Yes-associated Protein (YAP) (17). Phosphorylated (p-)YAP is sequestered in the cytoplasm, which decreases transcription of downstream genes in the nucleus (18). By contrast, inactivation of the Hippo pathway increases nuclear translocation of YAP, where YAP interacts with other transcription factors, such as tafazzin (19), to activate the transcription of target genes (18). Recently, YAP was found to be associated with chondrocyte differentiation. YAP promotes chondrogenic phenotype maintenance of rat growth plate chondrocytes and cartilage development in mice $(20,21)$.

Hypoxia inducible factor- $1 \alpha$ (HIF-1 $\alpha$ ) is a key regulatory factor involved in the adaptation process of cells to different oxygen partial pressures (22). The deletion of HIF-1 $\alpha$ leads to chondrocyte death in a hypoxic developmental growth plate, which suggests that HIF-1 $\alpha$ is essential for chondrocyte survival (23). HIF-1 $\alpha$ also regulates collagen synthesis and modification in chondrocyte differentiation (24). Both YAP and HIF- $1 \alpha$ are methylated by SETD7 $(25,26)$. In hepatocarcinoma cells, YAP forms a complex with HIF-1 $\alpha$ and binds to the promoter of the pyruvate kinase isoenzyme 2 (PKM2) gene to promote its transcription (27).

It was hypothesized that SETD7 may serve an important role in chondrocyte differentiation in hypoxic condition. SETD7, YAP and HIF-1 $\alpha$ may form a regulatory network during chondrocyte differentiation. Therefore, the objective of the present study was to investigate the regulatory role of SETD7 in chondrocyte differentiation and its mechanism.

\section{Materials and methods}

Cell culture. ATDC5 cells were purchased from the American Type Culture Collection (ATCC) cell bank and grown in Dulbecco's modified Eagle's medium/F12 (DMEM:F12, 1:1) supplemented with $10 \%(\mathrm{v} / \mathrm{v})$ fetal bovine serum (FBS; both Gibco; Thermo Fisher Scientific, Inc.), $100 \mathrm{U} / \mathrm{ml}$ penicillin G and $100 \mathrm{mg} / \mathrm{ml}$ streptomycin (HyClone; Cytiva). ATDC5 cells were cultured at $37^{\circ} \mathrm{C}$ with either $1 \%$ (low) or $20 \% \mathrm{O}_{2}$ (high oxygen tension).

293T cells were purchased from the ATCC cell bank and grown in Roswell Park Memorial Institute (RPMI)-1640 medium (Gibco; Thermo Fisher Scientific, Inc.) supplemented with $10 \%$ FBS (Gibco; Thermo Fisher Scientific, Inc.) at $37^{\circ} \mathrm{C}$ with $5 \% \mathrm{CO}_{2}$.

Viral infection. Viral packaging and infection were performed as described previously (11). SETD7 short hairpin (sh)RNA and non-specific control (NC) plasmids were purchased from Jintuosi Biological Technology Co., Ltd. The target sequences of SETD7 shRNA and NC were 5'-GGGATA TTACGTGGACGAT-3' and 5'-TACTGTTAGGATCAGG AGG-3', respectively. shRNA or NC plasmids (both $2.4 \mu \mathrm{g}$ ), as well as two helper vectors (pMD2G:pSPAX2:shRNA=1:2:4, were transfected into 2nd generation 293T cells using Neofect transfection reagent [Neofect (Beijing) Biotech Co., Ltd.] at $37^{\circ} \mathrm{C}$ for $48 \mathrm{~h}$. The viral supernatant was collected following centrifugation at $25^{\circ} \mathrm{C}(4,000 \mathrm{x} \mathrm{g} ; 3 \mathrm{~min})$ after $48 \mathrm{~h}$ and applied to transfect ATDC5 in the presence of $10 \mu \mathrm{g} / \mathrm{ml}$ polybrene (Sigma-Aldrich; Merck KGaA) at $37^{\circ} \mathrm{C}$ for $24 \mathrm{~h}$ at $\mathrm{MOI}=10$.
The viral supernatant was removed and changed for fresh growth medium after $24 \mathrm{~h}$ transfection. ATDC5 cells were inoculated and subcultured once for subsequent experiments.

Chondrogenic induction of cells. For chondrogenic differentiation, ATDC5 cells were seeded into 24-well plates at a density of $2 \times 10^{4}$ cells $/ \mathrm{cm}^{2}$ and grown in DMEM:F12 at $37^{\circ} \mathrm{C}$. At $70-90 \%$ confluence, growth medium was replaced with chondrogenic differentiation medium supplemented with $1 \mathrm{x}$ insulin-transferrin-selenium (Corning, Inc.). The medium was replaced every other day and cells were cultured for 14 days at $37^{\circ} \mathrm{C}$. Micromass culturing was performed as previously described (28). Briefly, ATDC5 cells were resuspended in DMEM:F12 at a density of $2 \times 10^{7}$ cells $/ \mathrm{ml}$. The cell suspension (20 $\mu \mathrm{l})$ was transferred into the middle of 24-well plate for $3 \mathrm{~h}$ at $37^{\circ} \mathrm{C}$ and chondrogenic differentiation medium was added for 14 days at $37^{\circ} \mathrm{C}$.

Immunofluorescence (IF) staining of cells. For IF staining, ATDC 5 cells were fixed at $25^{\circ} \mathrm{C}$ with $4 \%$ paraformaldehyde for $15 \mathrm{~min}$, permeabilized with $0.1 \%$ Triton X-100 for $5 \mathrm{~min}$ and blocked at $25^{\circ} \mathrm{C}$ with $0.1 \%$ BSA for $1 \mathrm{~h}$. The cells were incubated with primary antibodies against HIF-1 $\alpha$ (1:200; Abcam; cat. no. ab16066), YAP (1:100; Cell Signaling Technology, Inc.; cat. no. 4912S) or SETD7 (1:50; Abcam; cat. no. ab14820) overnight at $4^{\circ} \mathrm{C}$. The cells were rinsed three times with PBS and incubated with the corresponding secondary antibodies (Alexa Fluor ${ }^{\circledast}$ 488- or 594-conjugated goat anti-rabbit or anti-mouse IgG; both 1:1,000; both Abcam; cat. nos. ab150113 and ab150080, respectively). Next, the cells were rinsed with PBS three times and stained with $10 \mu \mathrm{g} / \mathrm{ml}$ DAPI for $5 \mathrm{~min}$ at $25^{\circ} \mathrm{C}$. Images were captured with a laser scanning confocal microscope (x400 magnification; Zeiss $\mathrm{GmbH}$; cat. no. LSM780). All experiments were performed in triplicate.

$R N A$ extraction and reverse transcription-quantitative $(R T-q)$ $P C R$. Total RNA from ATFC5 cells was extracted using an RNA extraction kit (Shanghai Yishan Biological Technology Co., Ltd.) according to the manufacturer's instructions. Concentration and quality of the total RNA samples were measured using a Nanodrop2000 (Thermo Fisher Scientific, Inc.). Complementary DNA was synthesized from $1 \mu \mathrm{g}$ total RNA using a PrimeScript RT-PCR kit (Takara Bio, Inc.; cat. no. RR047A) following the manufacturer's protocol. RT-qPCR was performed using the PrimeScript RT-PCR kit (Takara Bio, Inc.; cat. no. RR820A). The primers are listed in Table I. The thermocycling conditions were set as follows: Initial denaturation for $30 \mathrm{sec}$ at $95^{\circ} \mathrm{C}$; followed by 40 cycles of $95^{\circ} \mathrm{C}$ for $5 \mathrm{sec}, 60^{\circ} \mathrm{C}$ for $30 \mathrm{sec}$ and $95^{\circ} \mathrm{C}$ for $5 \mathrm{sec}$; melting at $65^{\circ} \mathrm{C}$ for $60 \mathrm{sec}$ and $97^{\circ} \mathrm{C}$ for $1 \mathrm{sec}$ and cooling at $50^{\circ} \mathrm{C}$ for $30 \mathrm{sec}$. Relative mRNA expression of target genes was calculated using the $2^{-\Delta \Delta \mathrm{Ca}}$ method (13). The experiments were performed in triplicate and repeated three times.

Protein extraction and western blotting. The cytoplasmic and nuclear proteins from ATDC5 cells were isolated using a nuclear and cytoplasmic protein extraction kit (Beyotime Institute of Biotechnology; cat. no. P0028) according to the manufacturer's instructions. The total protein from ATDC5 
Table I. Primer sequences used for reverse transcription-quantitative PCR.

\begin{tabular}{|c|c|c|}
\hline Gene & Species & Primer sequence, $5^{\prime} \rightarrow 3^{\prime}$ \\
\hline SETD7 & Mouse & $\begin{array}{l}\text { Forward TCCAAGGTAGCAGTTGGACCTAA } \\
\text { Reverse CCAAGGAGGCACAGTACTTGG }\end{array}$ \\
\hline YAP & Mouse & $\begin{array}{l}\text { Forward ATTTCGGCAGGCAATACGGA } \\
\text { Reverse TGCTCCAGTGTAGGCAACTG }\end{array}$ \\
\hline HIF- $1 \alpha$ & Mouse & $\begin{array}{l}\text { Forward AGCACAGTTACAGTATTCCAGCAGAC } \\
\text { Reverse TCATCAGTGGTGGCAGTGGTAGT }\end{array}$ \\
\hline COL2A1 & Mouse & $\begin{array}{l}\text { Forward GGCCAGGATGCCCGAAAATTA } \\
\text { Reverse GGCTGCAAAGTTTCCTCCAC }\end{array}$ \\
\hline SOX9 & Mouse & $\begin{array}{l}\text { Forward CTCCTACTACAGCCACGCAG } \\
\text { Reverse GCTGTGTGTAGACGGGTTGT }\end{array}$ \\
\hline Aggrecan & Mouse & $\begin{array}{l}\text { Forward AGCTTGAGGGGGAAGTGTTC } \\
\text { Reverse GGTTGACGATGGGGTATCGG }\end{array}$ \\
\hline GLUT1 & Mouse & $\begin{array}{l}\text { Forward ACCACCTCACТCСТGTTACTТАССТ } \\
\text { Reverse ATCCAААССТССТАСССТСААТССА }\end{array}$ \\
\hline LDHA & Mouse & $\begin{array}{l}\text { Forward TAGGCTACAACAGGATTCTAGGTGGAG } \\
\text { Reverse GTCAGAGGTGGCAGAACTATTTC }\end{array}$ \\
\hline PGK1 & Mouse & $\begin{array}{l}\text { Forward GAGCCAAGTCGGTAGTCCTTATGAG } \\
\text { Reverse CACAGTCCTTCAAGAACAGAACATCCT }\end{array}$ \\
\hline PKM2 & Mouse & $\begin{array}{l}\text { Forward GTGCCGCCTGGACATTGATTCA } \\
\text { Reverse AGTTCAGACGAGCCACATTCATTCC }\end{array}$ \\
\hline $18 \mathrm{~S}$ & Mouse & $\begin{array}{l}\text { Forward GGCGCCCCCTCGATGCTCTTAG } \\
\text { Reverse GCTCGGGCCTGCTTTGAACACTCT }\end{array}$ \\
\hline GAPDH & Mouse & $\begin{array}{l}\text { Forward TTGCAGTGGCAAAGTGGAGA } \\
\text { Reverse GATGGGCTTCCCGTTGATGA }\end{array}$ \\
\hline
\end{tabular}

SETD7, SET domain containing 7; YAP, Yes-associated protein; HIF-1 $\alpha$, hypoxia inducible factor-1 $\alpha$; COL2A1, collagen II, $\alpha 1$; SOX9, SRY-related box gene 9; GLUT1, glucose transporter 1; LDHA, lactate dehydrogenase A; PGK1, phosphoglycerate kinase 1; PKM2, pyruvate kinase isoenzyme 2 .

cells was collected with RIPA buffer (ProteinTech Group, Inc.; cat no. PR20001), mixed with loading buffer, and heated at $95^{\circ} \mathrm{C}$ for $10 \mathrm{~min}$. The protein concentration was determined via bicinchoninic acid assay kit (Thermo Fisher Scientific, Inc.; cat. no. 23227).

Proteins were separated by sodium dodecyl sulfate-polyacrylamide $10 \%$ gel electrophoresis (GenScript; cat. no. M00665) and transferred to nitrocellulose membranes. The membranes were blocked at $25^{\circ} \mathrm{C}$ using $5 \%$ skimmed milk or $5 \%$ BSA for $60 \mathrm{~min}$ and then incubated with primary antibodies against SETD7 (1:1,000; Abcam; cat. no. ab14820), HIF-1 $\alpha$ (1:2,000; Abcam; cat. no. ab16066), large tumor suppressor 1 (LATS1; 1:1,000; Cell Signaling Technology, Inc.; cat. no. 3477), p-LATS1 (1:1,000; Cell Signaling Technology, Inc.; cat. no. 8654), YAP (1:1,000; Cell Signaling Technology, Inc.; cat. no. 4912s), p-YAP (1:1,000; Cell Signaling Technology, Inc.; cat. no. 4911s), $\beta$-actin (1:1,000; ABclonal Biotech Co., Ltd.; cat. no. AC004), Lamin B (1:1,000; Weiao Biotechnology Co., Ltd.; cat. no. WB0199) or $\beta$-tubulin (1:1,000; Absin; cat. No. abs830032) at $4^{\circ} \mathrm{C}$ overnight, followed by secondary antibodies (horseradish peroxidase-conjugated goat anti-rabbit or anti-mouse IgG; both 1:10,000; both ABclonal Biotech Co., Ltd.; cat nos. AS063 and AS064, respectively) for $1 \mathrm{~h}$ at $25^{\circ} \mathrm{C}$.
The primary and secondary antibodies were diluted in 5\% BSA. Protein bands on the membranes were visualized using a Western Bright ECL HRP substrate kit (Advansta, Inc.). ImageJ (V 1.8.0; National Institutes of Health) was used for densitometry. All the experiments were performed in triplicate.

Alcian blue staining. For alcian blue staining, ATDC5 cells were cultured in chondrogenic induction medium at a density of $2 \times 10^{4}$ cells $/ \mathrm{ml}$ in 24 -well plates for 14 days at $25^{\circ} \mathrm{C}$. The cells were fixed at $25^{\circ} \mathrm{C}$ with $4 \%$ (w/v) paraformaldehyde for $15 \mathrm{~min}$. The cells were washed twice with PBS and stained for $30 \mathrm{~min}$ at $4^{\circ} \mathrm{C}$ with $0.5 \%$ alcian blue dye (Sigma-Aldrich; Merck $\mathrm{KGaA}$ ) in $1 \mathrm{~mol} / 1 \mathrm{HCl}$. After staining, cells were washed twice with distilled water and observed under a light microscope (x40 magnification; Axio Observer Z1; Zeiss GmbH).

Co-immunoprecipitation (Co-IP). ATDC5 cells at a density of $2 \times 10^{7}$ cells $/ \mathrm{ml}$ were pretreated at $25^{\circ} \mathrm{C}$ with $5 \mu \mathrm{M} \mathrm{MG} 132$ for $6 \mathrm{~h}$ after transfection. The cells were then collected and incubated with $300 \mu 1$ lysis buffer (Beyotime Institute of Biotechnology; cat. no. P0013) containing protease inhibitors for $40 \mathrm{~min}$ on ice. The supernatant was collected following centrifugation at $25^{\circ} \mathrm{C}(4,000 \mathrm{x} \mathrm{g} ; 5 \mathrm{~min})$ and $2 \mu \mathrm{g}$ HIF-1 $\alpha$ (1:2,000; Abcam; 
A

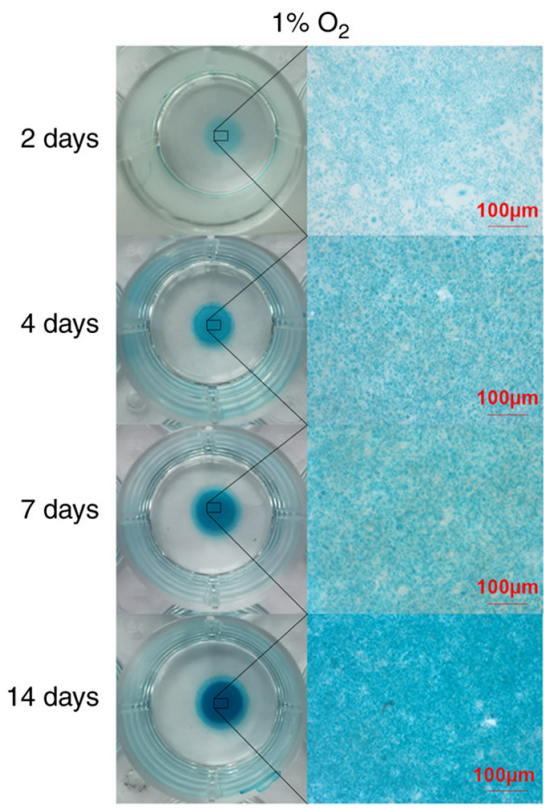

B

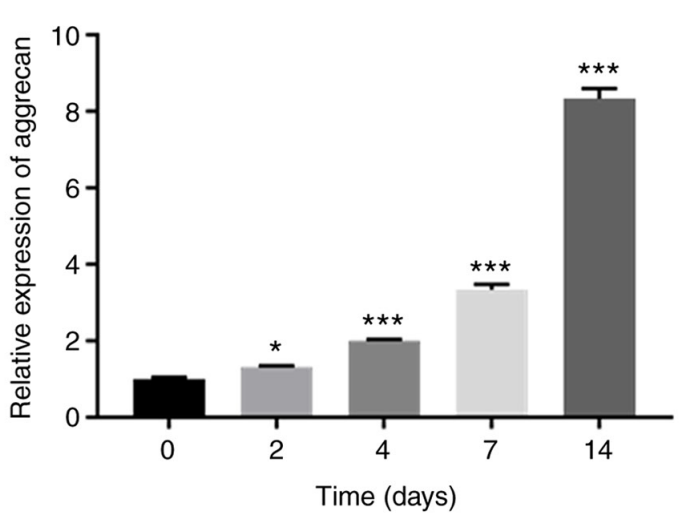

D

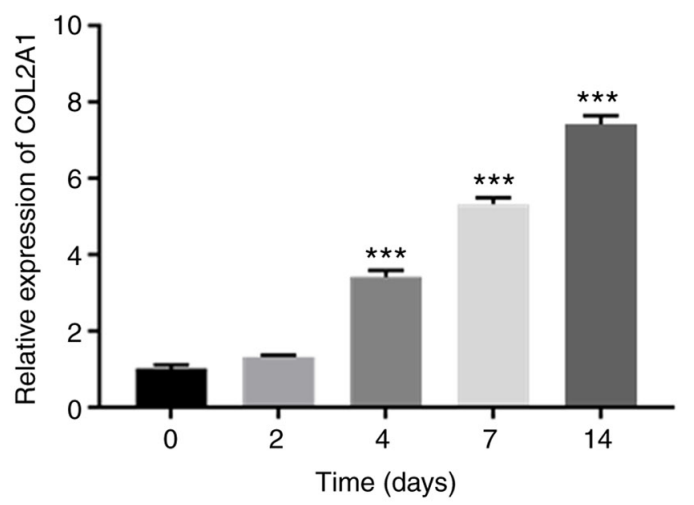

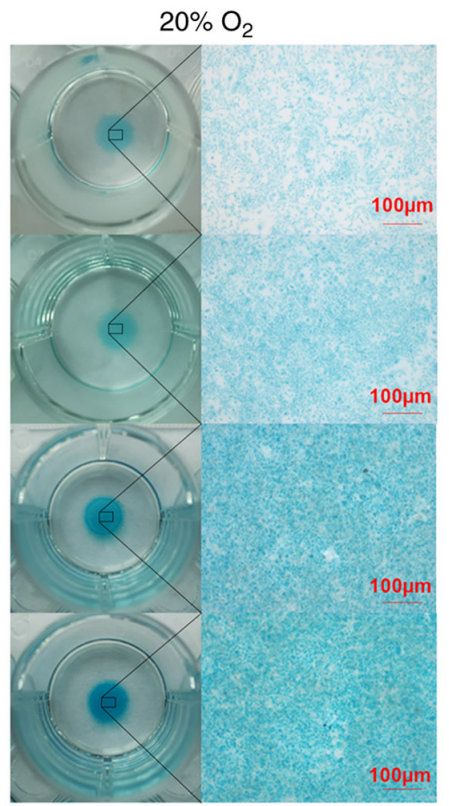

C

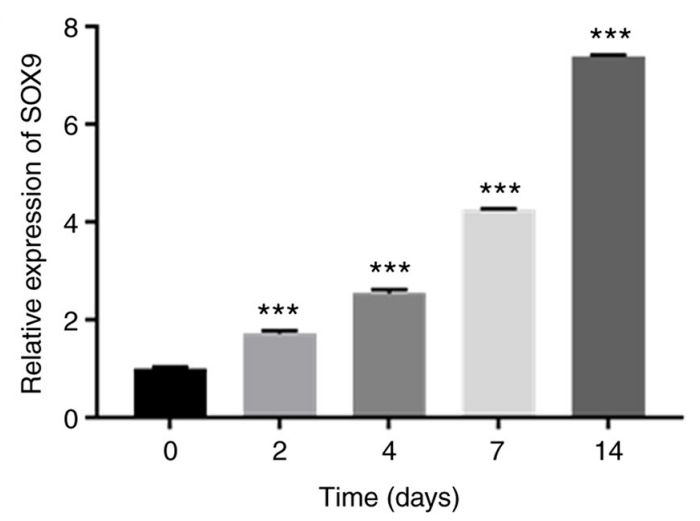

E

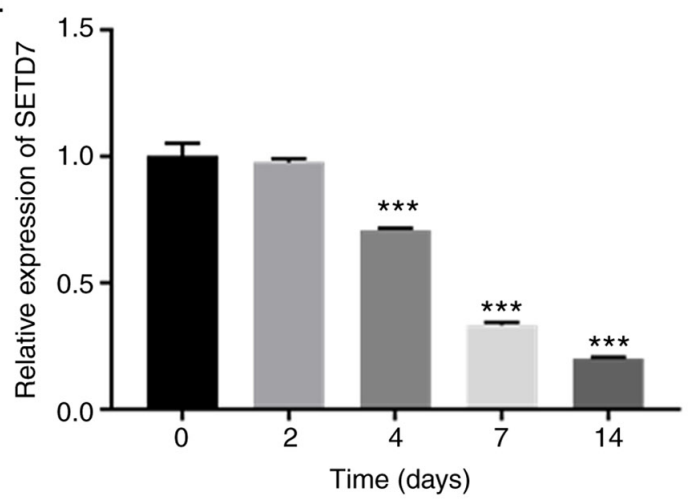

Figure 1. mRNA expression of SETD7 decreases during chondrogenic differentiation. (A) Alcian blue staining of differentiated ATDC5 cells cultured in micromass at 1 and $20 \% \mathrm{O}_{2}$. Scale bar, $100 \mu \mathrm{m}$. mRNA expression of (B) aggrecan, (C) SOX9, (D) COL2A1 and (E) SETD7 during chondrogenic differentiation at $1 \% \mathrm{O}_{2}$. Results are representative of $\geq 3$ independent experiments. ${ }^{*} \mathrm{P}<0.05,{ }^{* * *} \mathrm{P}<0.001$ vs. 0 days. SETD7, SET domain containing 7 ; HIF-1 $\alpha$, hypoxia inducible factor- $1 \alpha$; COL2A1, collagen II, $\alpha 1$; SOX9, SRY-related box gene 9.

cat. no. ab16066), YAP (1:1,000; Cell Signaling Technology, Inc.; cat. no. 4912s) or IgG (1:1,000; ProteinTech Group, Inc.; cat. no. B900620) antibody was added. The samples $(300 \mu \mathrm{l})$ were then incubated at $4^{\circ} \mathrm{C}$ overnight. Next, $20 \mu \mathrm{l}$ protein A/G-agarose beads (Santa Cruz Biotechnology, Inc.) was added and the samples were rocked for $3 \mathrm{~h}$ at $4^{\circ} \mathrm{C}$. The pelleted cells were collected following centrifugation at $25^{\circ} \mathrm{C}$ (4,000 x g; $5 \mathrm{~min})$ and washed three times with $500 \mu \mathrm{l}$ lysis buffer. Finally, precipitate was boiled with $40 \mu 1$ loading buffer for $5 \mathrm{~min}$ and analyzed by western blotting as aforementioned. The experiments were repeated in triplicate.

Extracellular acidification rate (ECAR). ECAR was measured using a Seahorse XF glycolysis stress test kit according to the manufacturer's protocol and a Seahorse XF 96 Extracellular Flux Analyzer (Seahorse Bioscience; Agilent Technologies, Inc.). In brief, ATDC5 cells $\left(2 \times 10^{4}\right.$ cells/well) were plated in a Seahorse XF 96-well cell culture plate. The loaded sensor 
A
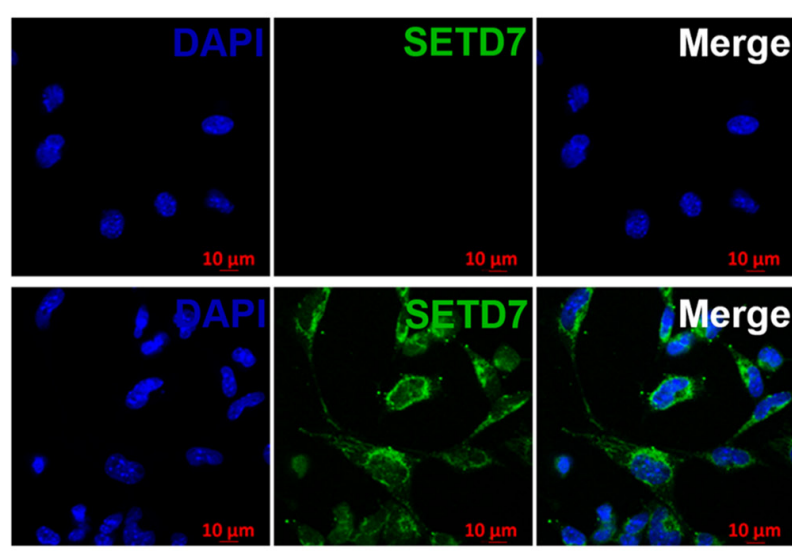

B
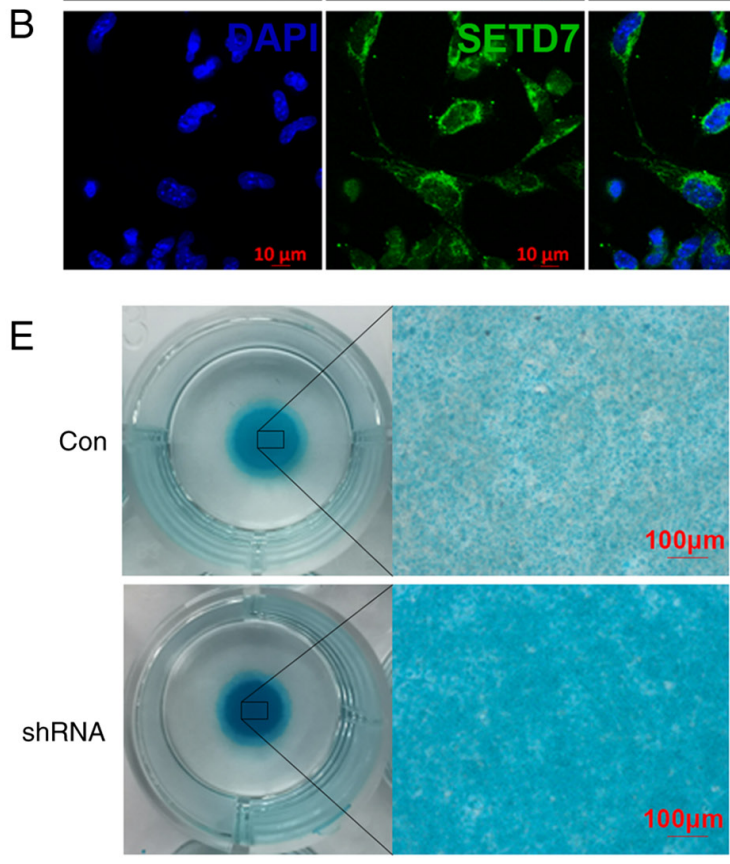

G

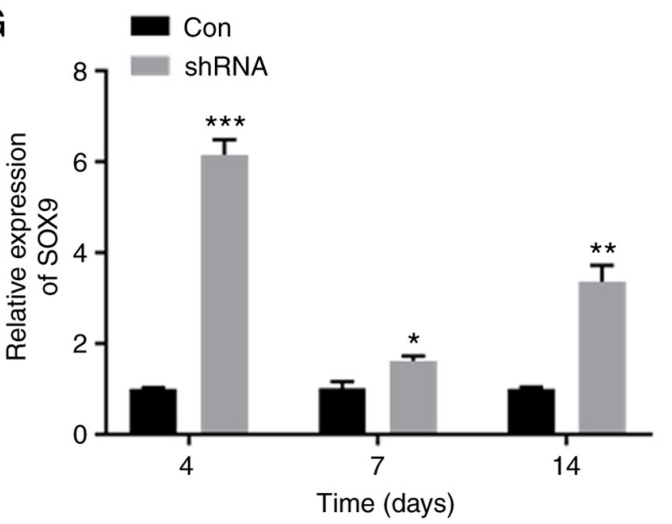

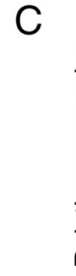

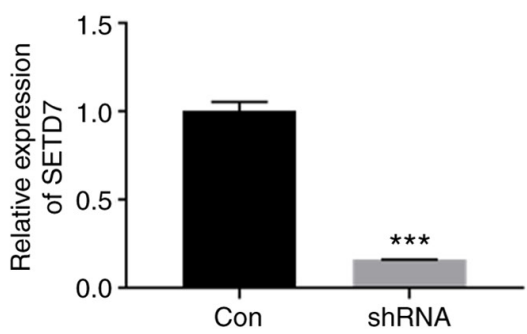

D

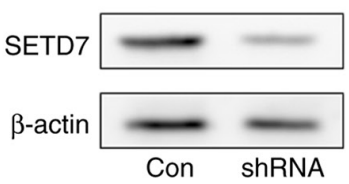

$\mathrm{F}$
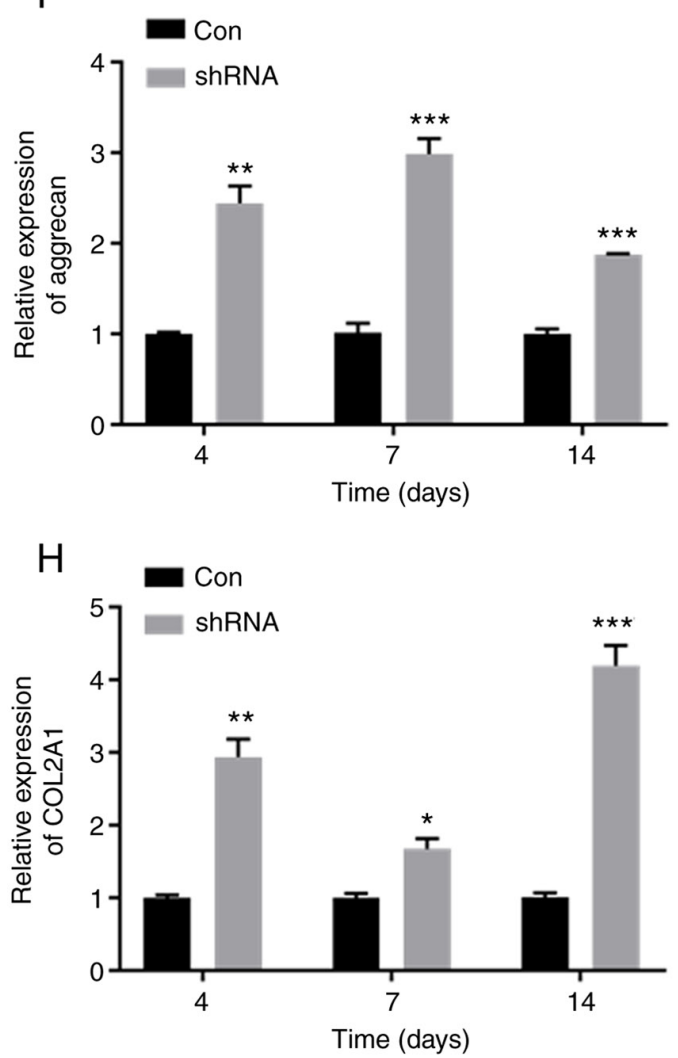

Figure 2. Knocking down SETD7 activates chondrogenic differentiation. (A) Immunofluorescence staining of ATDC5 cells at $1 \%$ O $\mathrm{O}_{2}$ incubated with secondary antibodies and DAPI. (B) Immunofluorescence staining with SETD7 primary antibody, secondary antibodies and DAPI in ATDC5 cells at $1 \% \mathrm{O}_{2}$. (C) mRNA expression and (D) protein levels of SETD7 after knocking down SETD7 at 1\% $\mathrm{O}_{2}$. (E) Alcian blue staining after knocking down SETD7 in cells cultured in micromass at $1 \% \mathrm{O}_{2}$. mRNA expression of $(\mathrm{F})$ aggrecan, $(\mathrm{G}) \mathrm{SOX} 9$ and $(\mathrm{H})$ COL2A1 after knocking down $\mathrm{SETD} 7$ at $1 \% \mathrm{O}_{2} .{ }^{*} \mathrm{P}<0.05,{ }^{* *} \mathrm{P}<0.01,{ }^{* * *} \mathrm{P}<0.001$ vs. con. SETD7, SET domain containing 7; HIF-1 $\alpha$, hypoxia inducible factor-1 $\alpha$; COL2A1, collagen II, $\alpha 1$; SOX9, SRY-related box gene 9; con, control; sh, short hairpin.

cartridge with the utility plate was placed into the instrument for calibration, then glucose, oligomycin and 2-deoxyglucose were sequentially added to each well at 20,40 and $60 \mathrm{~min}$. ECAR data were assessed using Seahorse XF-96 Wave (V 2.6; Seahorse Bioscience; Agilent Technologies, Inc.) software. The tests were performed in triplicate.

Determination of lactate and glucose levels. Lactic acid and glucose levels in ATDC5 cells treated at $37^{\circ} \mathrm{C}$ for $2 \mathrm{~h}$ in the presence or absence of PFI-2 (10 $\mu \mathrm{M}$, MedChemExpress; cat. no. HY-18627A), a specific inhibitor of SETD7, were determined using a lactic acid assay kit II (cat. no. MAK065-1KT) and highly sensitive glucose assay kit (both Sigma-Aldrich; Merck KGaA; cat. no. MAK181-1KT), respectively, according to the manufacturer's instructions. ATDC5 cells at a density of $2 \times 10^{7}$ cells $/ \mathrm{ml}$ were homogenized on ice with a glucose test or lactic acid buffer. The supernatant was collected following centrifugation at $25^{\circ} \mathrm{C}$ (3,280 x g; $5 \mathrm{~min})$. Ultrafiltration tubes (10 kDa) were used to remove proteins from the sample. Fluorescence intensity (excitation, 535; emission, $587 \mathrm{~nm}$ ) was measured after diluting the sample with glucose determination buffer and the glucose level was assessed. The absorbance value at $450 \mathrm{~nm}$ was measured after sample was diluted with lactic acid determination buffer solution and lactic acid level was assessed. 
A

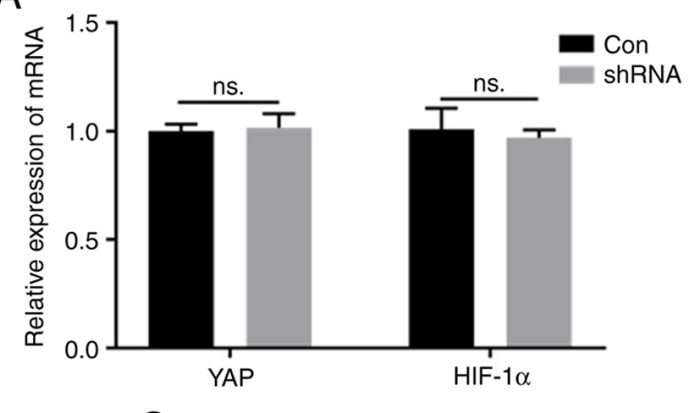

C
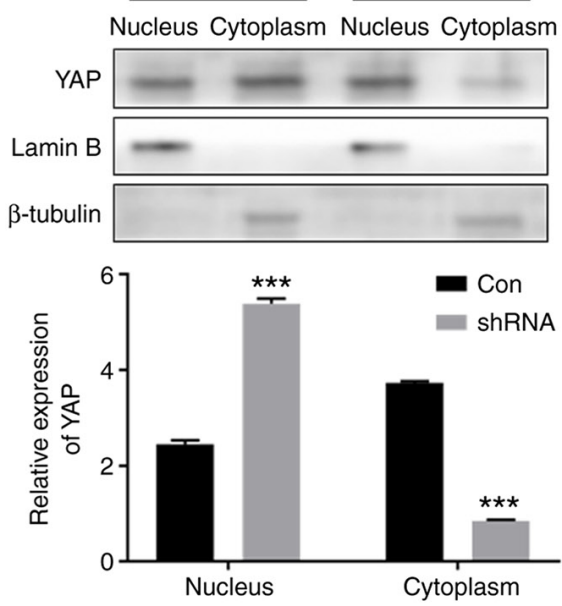

E
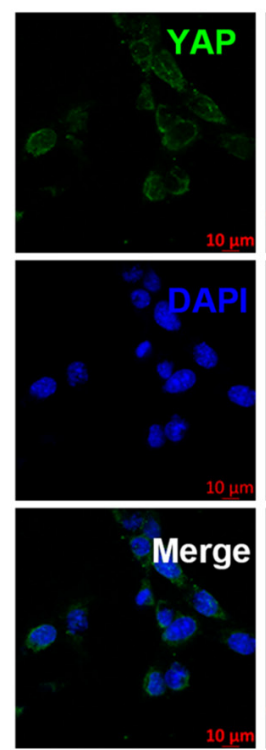

Con
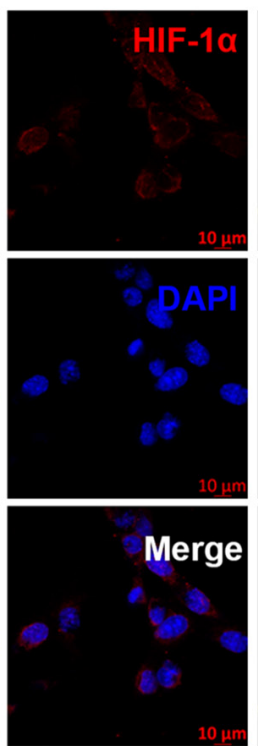

B
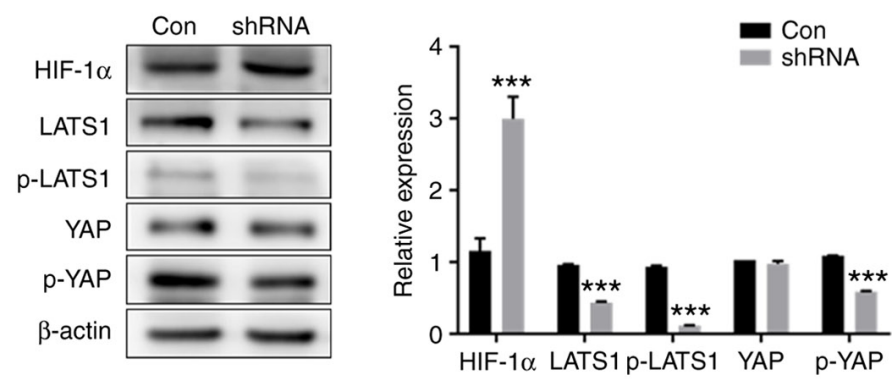

D
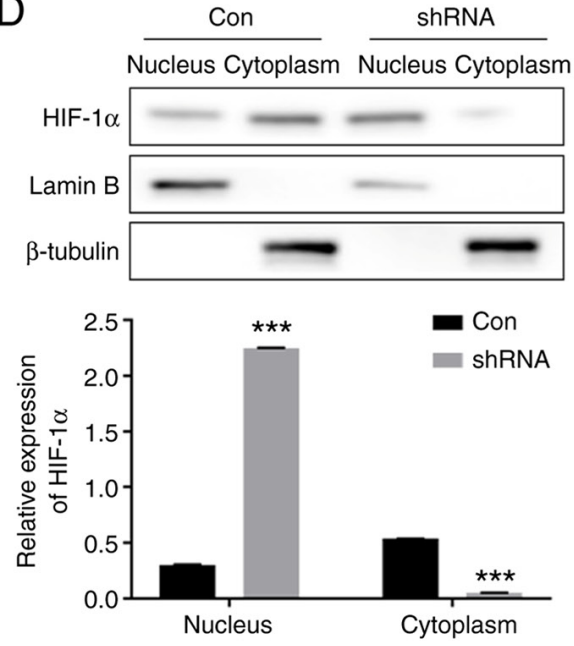

shRNA
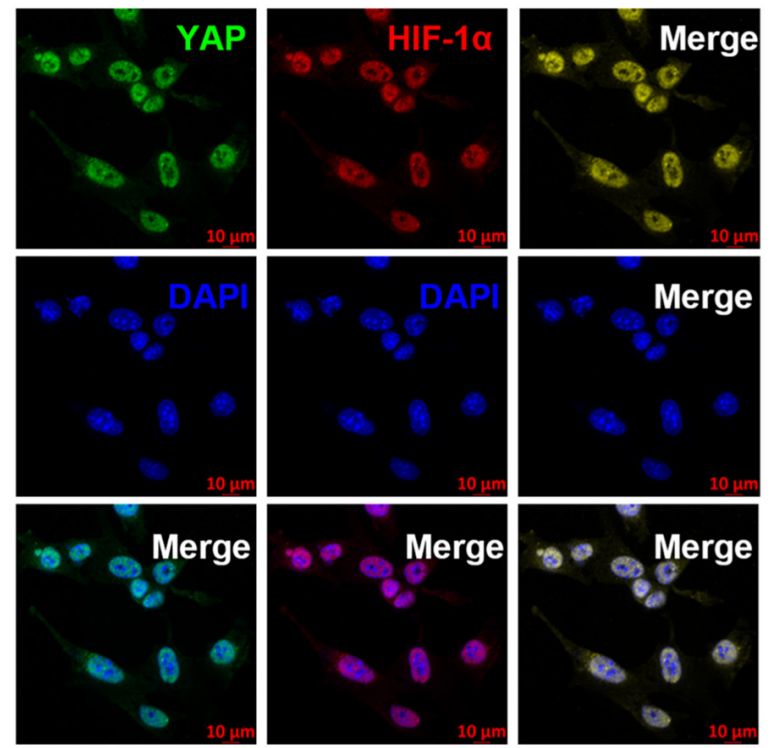

Figure 3. Knocking down SETD7 activates YAP and HIF-1 $\alpha$. (A) mRNA expression of YAP and HIF-1 $\alpha$ after knocking down SETD7 at $1 \%$ O 2 . (B) Protein levels of LATS1, p-LATS1, YAP, p-YAP and HIF-1 $\alpha$ after knocking down SETD7 at $1 \% \mathrm{O}_{2}$. Protein levels of (C) YAP and (D) HIF-1 $\alpha$ in the nucleus and cytoplasm after knocking down SETD7 at $1 \% \mathrm{O}_{2}$. Lamin B and $\beta$-tubulin were used as the reference for cytoplasmic and nuclear protein, respectively. (E) Immunofluorescence staining of YAP and HIF-1 $\alpha$ after knocking down SETD7 at $1 \% \mathrm{O}_{2}{ }^{*}{ }^{* * *} \mathrm{P}<0.001$ vs. con. SETD7, SET domain containing 7; YAP, Yes-associated protein; HIF-1 $\alpha$, hypoxia inducible factor-1 $\alpha$; LATS1, large tumor suppressor 1; p-, phosphorylated; con, control; ns, not significant; sh, short hairpin.

Cycloheximide (CHX) chase test. CHX was dissolved in PBS to a concentration of $100 \mu \mathrm{g} / \mathrm{ml}$. ATDC5 cells at a density of $2 \times 10^{7}$ cells $/ \mathrm{ml}$ were treated at $25^{\circ} \mathrm{C}$ with $\mathrm{CHX}$ for 0,2 and $4 \mathrm{~h}$ after being treated in the presence or absence of verteporfin (VP, $5 \mu \mathrm{M}$ ) at $37^{\circ} \mathrm{C}$ for $2 \mathrm{~h}$. The cells were collected and the protein levels of HIF-1 $\alpha$ were analyzed using western blotting as aforementioned.
Statistical analysis. Data are presented as the mean \pm SD of three independent experimental repeats. All tests were performed in triplicate. GraphPad Prism software (GraphPad Software, Inc.; V 8.0.1.244) was used for statistical analysis. Following tests of normality (Shapiro-Wilk test) and Levene's test for equality of variance, paired Student's t-test was used to assess the differences between the control and test groups. 

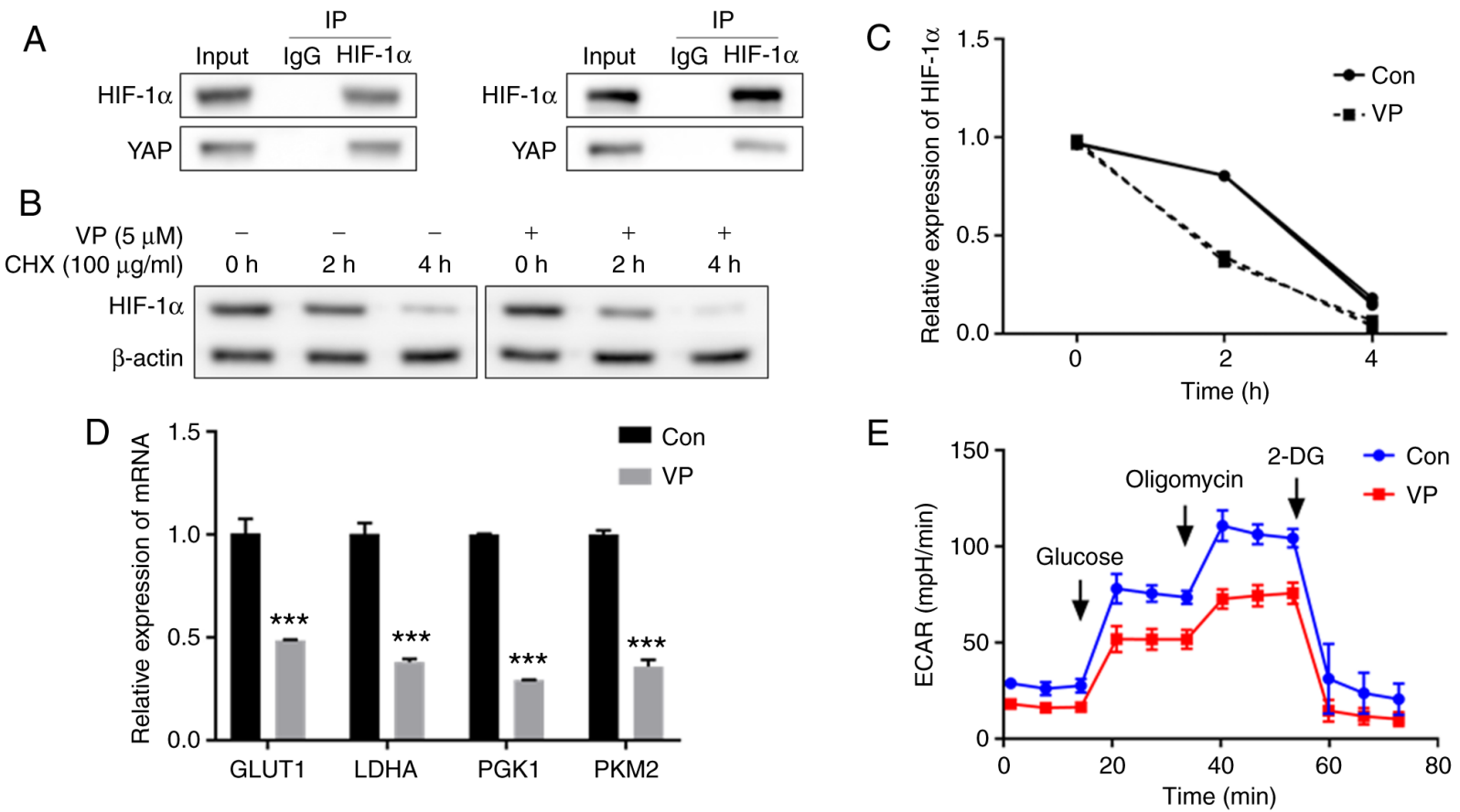

Figure 4. YAP combines with HIF-1 $\alpha$ following SETD7 knockdown. (A) IP results of YAP and HIF-1 $\alpha$ after knocking down SETD7. ATDC5 cells were pretreated with MG132 $(5 \mu \mathrm{M})$ for $6 \mathrm{~h}$ after transfection. Following ATDC5 cell pretreatment with VP and CHX, (B) western blotting was performed and (C) protein expression levels of HIF-1 $\alpha$ were assessed. (D) mRNA expression of glycolytic enzymes GLUT1, LDHA, PGK1 and PKM2 following YAP inhibition with VP. (E) ECAR decreased following YAP inhibition. ${ }^{* * *} \mathrm{P}<0.001$ vs. con. SETD7, SET domain containing 7; YAP, Yes-associated protein; HIF-1 $\alpha$, hypoxia inducible factor-1 $\alpha$; VP, verteporfin; IP, immunoprecipitation; CHX, cycloheximide; GLUT1, glucose transporter 1; LDHA, lactate dehydrogenase A; PGK1, phosphoglycerate kinase 1; PKM2, pyruvate kinase isoenzyme 2; ECAR, extracellular acidification rate; con, control; 2-DG, 2-deoxyglucose.

One- and two-way ANOVA followed by Dunnett's test or Bonferroni correction were used to analyze the differences of aggrecan, SOX9 and COL2A1 relative expression between multiple groups during cartilage induction and following SETD7 knockdown. Two-way ANOVA followed by Dunnett's test or Bonferroni's correction were used to analyze the differences between groups all other experiments. $\mathrm{P}<0.05$ was considered to indicate a statistically significant difference.

\section{Results}

Expression of SETD7 decreases during chondrogenic differentiation. Chondrocytes in monolayer and micromass culture exhibited greater alcian blue staining in $1 \% \mathrm{O}_{2}$ group (Fig. 1A). In monolayer culture, the expression levels of aggrecan, SRY-related box gene 9 (SOX9) and collagen II, $\alpha 1$ (COL2A1; chondrocyte differentiation markers) increased (Fig. 1B-D), while mRNA levels of SETD7 gradually decreased (Fig. 1E) during differentiation of ATDC5 cells in $1 \% \mathrm{O}_{2}$. These results indicated that expression of SETD7 decreased during chondrogenic differentiation.

SETD7 inhibits chondrogenic differentiation in a hypoxic environment. IF results showed that SETD7 was localized to the cytoplasm of ATDC5 cells (Fig. 2A and B). Following SETD7 knockdown (Fig. 2C and D), alcian staining was more pronounced (Fig. 2E) in monolayer and micromass culture and the expression levels of aggrecan, SOX9 and COL2A1 increased in monolayer culture (Fig. 2F-H). These results indicated that SETD7 inhibited chondrogenic differentiation in hypoxic environment.
SETD7 knockdown activates YAP and HIF-1 $\alpha$. In monolayer culture, the mRNA expression levels of YAP and HIF-1 $\alpha$ showed no change following silencing of SETD7 (Fig. 3A). Protein levels of LATS1, p-LATS1 (Ser909) and p-YAP (Ser127) decreased. Although the protein level of total YAP remained unchanged, localization of YAP in the nucleus increased (Fig. 3B and C). The protein levels of total and nuclear HIF-1 $\alpha$ in increased in the SETD7 knockdown group (Fig. 3B and D). IF results showed that nuclear localization of both YAP and HIF-1 $\alpha$ in ATDC5 cells increased following SETD7 silencing (Fig. 3E). These results indicated that SETD7 knockdown activated YAP and HIF-1 $\alpha$.

YAP and HIF-1 $\alpha$ form a complex. In monolayer culture, Co-IP showed that YAP bound to HIF-1 $\alpha$ (Fig. 4A). After inhibiting YAP with VP, a YAP specific inhibitor (29), the HIF-1 $\alpha$ content decreased at 2 and $4 \mathrm{~h}$ compared with the control group (Fig. 4B and C). These results indicated that YAP and HIF-1 $\alpha$ form a complex.

Effect of SETD7 on chondrocyte glycolysis. Following inhibition of YAP, mRNA levels of glucose transporter 1 (GLUT1), lactate dehydrogenase A (LDHA), phosphoglycerate kinase 1 (PGK1) and PKM2 in ATDC5 cells decreased (Fig. 4D), as well as the ECAR in monolayer culture (Fig. 4E).

After inhibiting SETD7 using PFI-2, a specific SETD7 inhibitor (30), glucose uptake, lactic acid production rate and ECAR of ATDC5 cells all increased in monolayer culture compared with the control (Fig. 5A-C). The mRNA expression of key glycolytic enzymes GLUT1, LDHA, PGK1 and PKM2 also increased in the SETD7-inhibited group in monolayer 
A

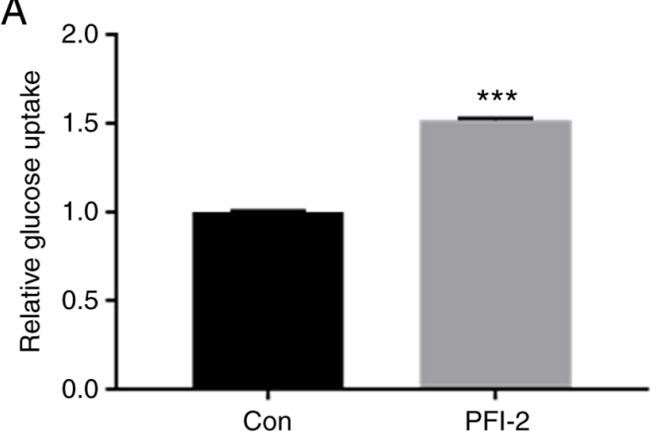

C

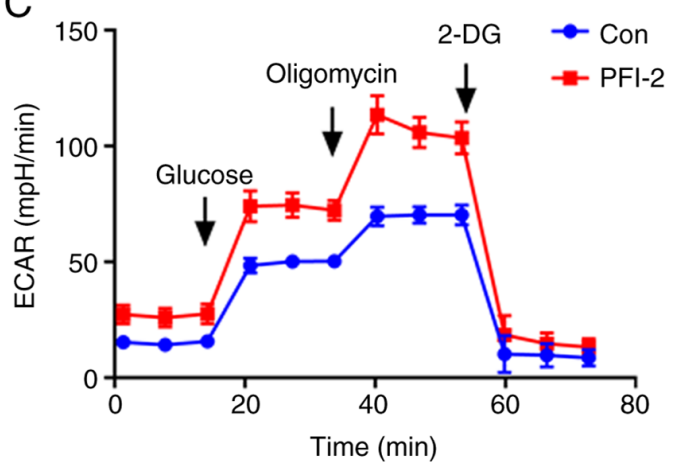

$\mathrm{B}$

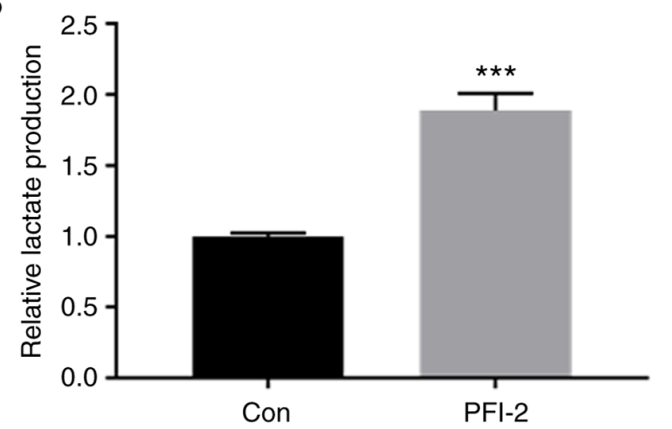

D

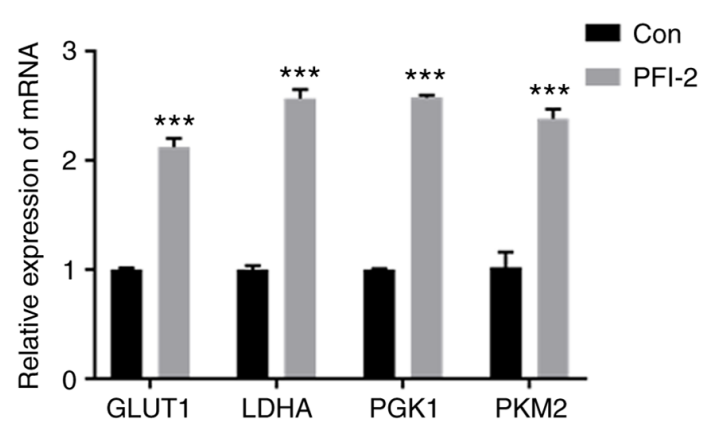

Figure 5. Effect of SETD7 on chondrocyte glycolysis. ATDC5 cells were pretreated with PFI-2 (40 nM) for $24 \mathrm{~h}$ to inhibit SETD7. (A) Glucose uptake and (B) lactic acid production increased after SETD7 was inhibited. (C) ECAR of control and PFI-2 groups. (D) mRNA expression levels of the key glycolysis enzymes GLUT1, LDHA, PGK1 and PKM2 of control and PFI-2 groups. ${ }^{* * * *} \mathrm{P}<0.001$ vs. con. SETD7, SET domain containing 7; GLUT1, glucose transporter 1; LDHA, lactate dehydrogenase A; PGK1, phosphoglycerate kinase 1; PKM2, pyruvate kinase isoenzyme 2; ECAR, extracellular acidification rate; con, control; 2-DG, 2-deoxyglucose.

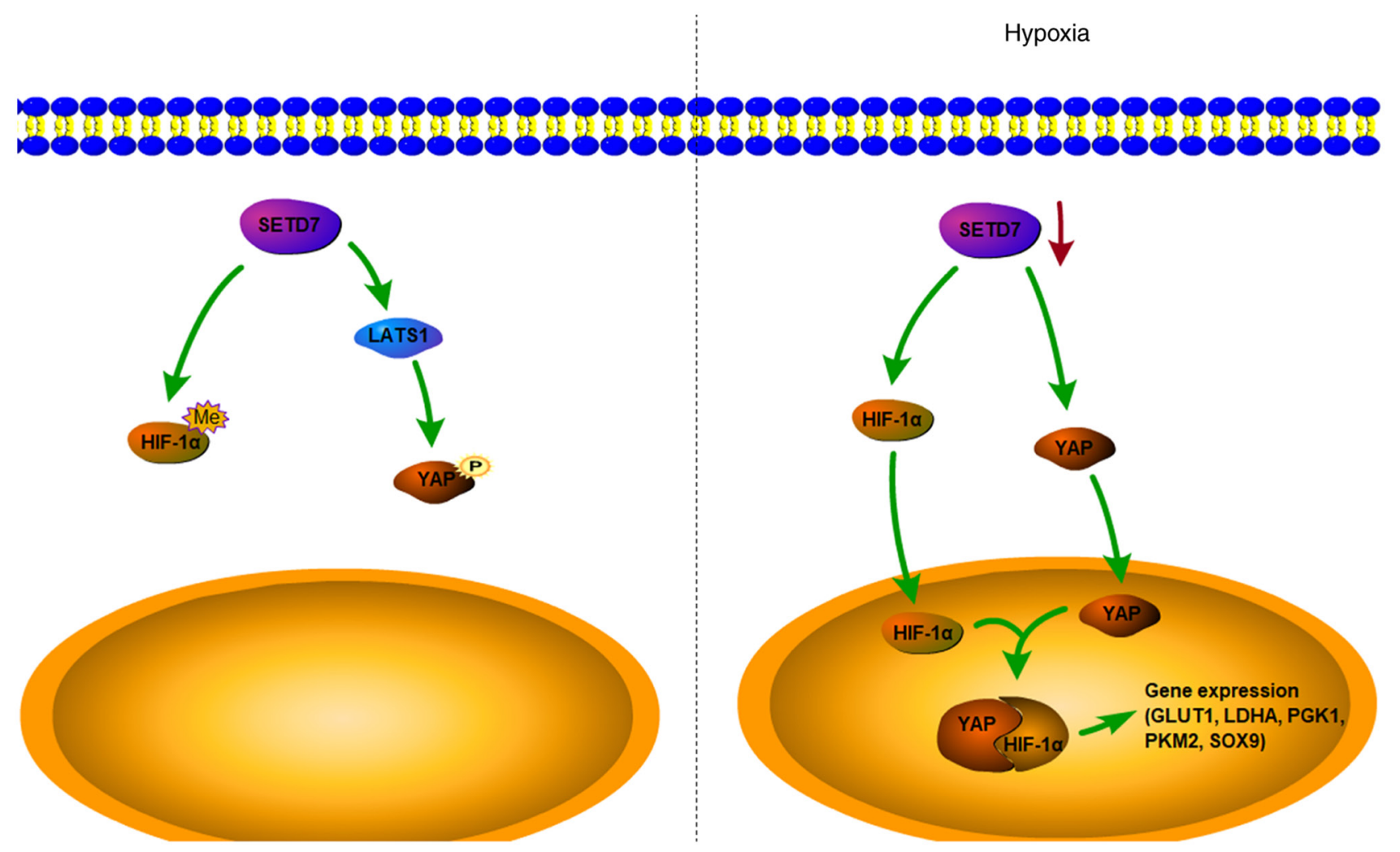

Figure 6. SETD7 regulates chondrocyte differentiation and glycolysis via the Hippo and HIF-1 $\alpha$. In normal conditions, SETD7 activates the Hippo signaling pathway, which phosphorylates YAP and retains it in the cytoplasm. In hypoxic conditions, expression of SETD7 is inhibited, resulting in increased YAP and HIF-1 $\alpha$ in the cytoplasm. The accumulated YAP and HIF-1 $\alpha$ translocate into the nucleus and combine to form a complex, which further promotes expression of glycolysis-associated genes and chondrogenic differentiation. SETD7, SET domain containing 7; YAP, Yes-associated protein; HIF-1 $\alpha$, hypoxia inducible factor-1 $\alpha$; GLUT1, glucose transporter 1; LDHA, lactate dehydrogenase A; PGK1, phosphoglycerate kinase 1; PKM2, pyruvate kinase isoenzyme 2; LATS1, large tumor suppressor 1; SOX9, SRY-related box gene 9; Me, methylation; P, phosphorylation. 
culture (Fig. 5D). These results indicated that SETD7 inhibited chondrocyte glycolysis.

\section{Discussion}

Cartilage tissue engineering has attracted attention for its potential to improve repair of cartilage defects (31). Chondrocytes tend to lose their phenotype and cartilage-forming ability under normal oxygen conditions in vitro (32). The cartilage-forming ability of chondrocytes is essential to the success of cartilage tissue engineering (33). Chondrocytes produce more functional extracellular matrix in hypoxic compared with normoxic environments (11). In the present study, chondrocytes exhibited better differentiation under hypoxic conditions in vitro. However, the mechanism of chondrocyte differentiation under low oxygen partial pressure remain unclear. The present study found that alcian staining was more pronounced in monolayer and micromass culture and the expression levels of aggrecan, SOX9 and COL2A1 increased in monolayer culture following SETD7 knockdown; this indicated that chondrocyte differentiation under low oxygen partial pressure was regulated by SETD7.

SETD7 was initially identified as a histone methyltransferase that catalyzes methylation of $\mathrm{H} 3 \mathrm{~K} 4$, thereby promoting transcriptional activation (34). Numerous non-histone substrates, such as YAP (35) and E2F1 (36), of SETD7 have recently been described as key factors in regulating cell differentiation and proliferation (37). In the present study, SETD7 mRNA expression gradually decreased during chondrocyte differentiation. The regulatory mechanism of SETD7 in chondrocyte differentiation was investigated by silencing SETD7 in ATDC5 cells. Following SETD7 knockdown, ATDC5 cells showed improved differentiation ability and increased expression levels of aggrecan, SOX9 and COL2A1. These results indicated that SETD7 served a negative role in chondrogenic differentiation.

Hippo signaling pathway regulates the morphology and cell differentiation of various organs, such as liver (38) and kidney (39). When the Hippo signal is activated, a series of phosphorylation reactions occur via MST and LAT kinases, culminating in YAP phosphorylation, which initiates cytoplasmic retention and ubiquitin-mediated degradation. The inactivation of Hippo pathway promotes YAP translocation to the nucleus (40). After entering the nucleus, YAP interacts with TEA domain transcription factors to activate the transcription of target genes and promote chondrocyte differentiation (18). Silencing SETD7 using a lentiviral vector system demonstrated that SETD7 prevented YAP from entering the nucleus and inhibited the chondrogenic differentiation ability of ATDC5 cells. Studies have shown that SETD7 binds to YAP to form a complex and methylate its lysine 494 residue, retaining it in the cytoplasm $(26,35)$. The biological effect of SETD7 inhibition of chondrogenic differentiation via inhibiting YAP may be caused by direct methylation of YAP or activation of Hippo signaling by SETD7 (41). The present study found that the expression of proteins associated with the Hippo signaling pathway increased after silencing SETD7, indicating that SETD7 activated the Hippo signaling pathway, resulting in phosphorylation of YAP protein to prevent it from entering the nucleus to perform its function, thus inhibiting chondrogenic differentiation of ATDC5 cells.
HIF-1 $\alpha$ is ubiquitous in human and mammalian cells, regulating glycolytic metabolism, angiogenesis and apoptosis in the absence of oxygen (42). When oxygen partial pressure is $<5 \%$, HIF- $1 \alpha$ accumulates in the cytoplasm and transfers to the nucleus, where it binds to hypoxic reaction elements and promotes downstream gene expression. HIF- $1 \alpha$ activates PDK-1 during anaerobic glycolysis, inhibits the aerobic respiratory chain and decreases formation of reactive oxygen species. When oxygen partial pressure $>5 \%$, prolyl hydroxylase domain-containing enzymes specifically hydroxylate proline residues of HIF-1 $\alpha$ (43). The hydroxylated HIF-1 $\alpha$ is degraded by proteasomes following ubiquitination (44). Recent studies have shown that HIF-1 $\alpha$ enhances expression of SOX9 induced by bone morphogenetic protein 2 and inhibits the expression of Runx 2 in mesenchymal stem cells, thereby promoting chondrogenesis and inhibiting osteogenesis $(45,46)$. Other studies suggested that HIF-1 $\alpha$ binding with hypoxia response elements promotes $\mathrm{SOX} 9$ transcription and thus maintains chondrocyte phenotype $(24,46)$. In the present study, HIF-1 $\alpha$ bound to YAP in the nucleus to form a complex, which promoted expression of glycolysis-associated enzymes, enhanced glycolysis metabolism and provided energy for chondrocyte proliferation and differentiation under hypoxia. However, the effect of HIF-1 $\alpha$ on phenotype maintenance and chondrogenic ability of chondrocytes remains to be further studied.

SETD7 methylates the lysine 494 residue of YAP, retaining it in the cytoplasm (26). HIF-1 $\alpha$ contains the R-S-K amino acid sequence, which is also recognized by SETD7 (47). A recent study showed that YAP forms a complex with HIF-1 $\alpha$ in hepatocellular carcinoma cells and binds to the promoter of the PKM2 gene to promote its transcription (27). Therefore, a regulatory network between SETD7, YAP and HIF-1 $\alpha$ in chondrocytes may be formed to regulate chondrocyte differentiation.

To investigate the association between SETD7, YAP and HIF-1 $\alpha$ in chondrocytes, SETD7 was silenced. The expression of p-YAP was significantly decreased after silencing SETD7, while total YAP was not increased; protein levels of LATS1 and p-LATS1, upstream regulators of YAP in the Hippo pathway, were decreased. These data implied that Hippo signaling may be inhibited by silencing SETD7. As YAP nuclear localization is a key regulatory mechanism for activating YAP (48), immunofluorescence staining was performed to examine cellular localization of YAP. Silencing SETD7 triggered notable YAP nuclear translocation in ATDC5 cells. Consistent with these data, cell fractionation showed more YAP protein accumulation in the nuclear fraction and less YAP protein in the cytoplasmic fraction of cells following SETD7 silencing. The results suggest that silencing SETD7 activated YAP and induced YAP translocation to the nucleus by inhibiting the Hippo pathway in ATDC5 cells. However, the increase of nuclear YAP was not significant, but the decrease in cytoplasmic YAP was significant after silencing SETD7 in ATDC5 cells. It has been reported that SETD7 binds to YAP in the cytoplasm to increase its stability (26). However, cytoplasmic YAP is degraded by hydroxylation after silencing SETD7. The reason why the increase of YAP in the nucleus was less than the decrease in the cytoplasm be associated with degradation of YAP after silencing SETD7. 
There was no difference in HIF-1 $\alpha$ transcription between ATDC5 cells in the SETD7-shRNA and control group, but HIF-1 $\alpha$ protein levels increased, indicating that HIF-1 $\alpha$ protein became more stable after silencing SETD7. This may be due to the ability of SETD7 to degrade HIF-1 $\alpha$, or because YAP entry to the nucleus makes HIF-1 $\alpha$ more stable. The results of IF showed that both YAP and HIF-1 $\alpha$ were located in the nucleus after silencing SETD7. The results of IP showed that YAP and HIF-1 $\alpha$ bound to each other. CHX assay showed that HIF-1 $\alpha$ was be stabilized by YAP. Thus, the increased HIF-1 $\alpha$ protein level after silencing SETD7 may be caused by the decreased SETD7, which degrades HIF- $1 \alpha$ and facilitates entry of YAP into the nucleus to bind to HIF-1 $\alpha$ and maintain its stability.

In previous studies, SETD7 was shown to be highly expressed in chondrocytes at 20 compared with $1 \% \mathrm{O}_{2}(13,49)$. The present study demonstrated that at $1 \% \mathrm{O}_{2}$, decreased SETD7 expression leads to inhibition of Hippo signaling and an increase in YAP entering the nucleus. YAP promotes the expression of genes associated with the differentiation of chondrocytes and maintains chondrocyte phenotype after entering the nucleus. It also binds and stabilizes HIF-1 $\alpha$ to promote glycolysis, which provides energy for chondrocyte differentiation (Fig. 6).

The present study demonstrated that hypoxia was conductive to the differentiation of chondrocytes. SETD7 inhibited glycolysis and differentiation of chondrocytes via the Hippo signaling pathway and HIF-1 $\alpha$. These findings may shed new light on cartilage tissue engineering and provide novel therapeutic targets of chondrogenic disease.

\section{Acknowledgements}

Not applicable.

\section{Funding}

The present study was supported by funds from the National Natural Science Foundation of China (grant nos. 81901025 and 82071156), the China Postdoctoral Science Foundation (grant no. 2019M653232), Guangdong Basic and Applied Basic Research Foundation (grant no. 2019A1515011326), and the Fundamental Research Funds for the Central Universities (grant no. 19ykpy82).

\section{Availability of data and materials}

The datasets used and/or analyzed during the current study are available from the corresponding author on reasonable request.

\section{Authors' contributions}

ML performed the experiments, collected and visualized data and wrote the manuscript. JN and JW performed the experiments and collected the data. QY performed the experiments, validated the data and wrote the manuscript. KZ analyzed the data. XJ conceptualized and supervised the study, provided resources, performed the methodology and wrote, reviewed and edited the manuscript. XJ and ML confirm the authenticity of all the raw data. All authors have read and approved the final version of the manuscript.

\section{Ethics approval and consent to participate}

Not applicable.

\section{Patient consent for publication}

Not applicable.

\section{Competing interests}

The authors declare that they have no competing interests.

\section{References}

1. Ma Q, Liao J and Cai X: Different sources of stem cells and their application in cartilage tissue engineering. Curr Stem Cell Res Ther 13: 568-575, 2018

2. Huang K, Li Q, Li Y, Yao Z, Luo D, Rao P and Xiao J: Cartilage tissue regeneration: The roles of cells, stimulating factors and scaffolds. Curr Stem Cell Res Ther 13: 547-567, 2018.

3. Shi W, Sun M, Hu X, Ren B, Cheng J, Li C, Duan X, Fu X, Zhang J, Chen $\mathrm{H}$ and Ao Y: Structurally and functionally optimized silk-fibroin-gelatin scaffold using 3D printing to repair cartilage injury in vitro and in vivo. Adv Mater 29, 2017.

4. Park IS, Jin RL, Oh HJ, Truong MD, Choi BH, Park SH, Park DY and Min BH: Sizable scaffold-free tissue-engineered articular cartilage construct for cartilage defect repair. Artif Organs 43: 278-287, 2019.

5. Ma B, Leijten JC, Wu L, Kip M, van Blitterswijk CA, Post JN and Karperien M: Gene expression profiling of dedifferentiated human articular chondrocytes in monolayer culture. Osteoarthritis Cartilage 21: 599-603, 2013.

6. Greuel S, Hanci G, Böhme M, Miki T, Schubert F, Sittinger M, Mandenius CF, Zeilinger K and Freyer N: Effect of inoculum density on human-induced pluripotent stem cell expansion in 3D bioreactors. Cell Prolif 52: e12604, 2019.

7. Tarahomi M, Vaz FM, Van straalen JP, Schrauwen FAP, van Wely M, Hamer G, Repping S and Mastenbroek S: The composition of human preimplantation embryo culture media and their stability during storage and culture. Hum Reprod 34: 1450-1461, 2019.

8. Jin GZ and Kim HW: Chondrogenic potential of dedifferentiated rat chondrocytes reevaluated in two- and three-dimensional culture conditions. Tissue Eng Regen Med 15: 163-172, 2017.

9. Oppenheimer H, Kumar A, Meir H, Schwartz I, Zini A, Haze A, Kandel L, Mattan Y, Liebergall M and Dvir-Ginzberg M: Set7/9 impacts COL2A1 expression through binding and repression of SirT1 histone deacetylation. J Bone Miner Res 29: 348-360, 2014.

10. Archer CW and Francis-West P: The chondrocyte. Int J Biochem Cell Biol 35: 401-404, 2003.

11. Huang X, Zhong L, Hendriks J, Post JN and Karperien M: Different response of human chondrocytes from healthy looking areas and damaged regions to IL1 $\beta$ stimulation under different oxygen tension. J Orthop Res 37: 84-93, 2019.

12. Yahiro K, HigashihoriI N and Moriyama K: Histone methyltransferase Setdb1 is indispensable for Meckel's cartilage development. Biochem Biophys Res Commun 482: 883-888, 2017.

13. Xiaoshi J, Maoquan L, Jjiwei W, Jinqiu N and Ke Z: SETD7 mediates the vascular invasion in articular cartilage and chondrocytes apoptosis in osteoarthriis. FASEB J 35: e21283, 2021.

14. Herz HM, Garruss A and Shilatifard A: SET for life: Biochemical activities and biological functions of SET domain-containing proteins. Trends Biochem Sci 38: 621-639, 2013.

15. Duan B, Bai J, Qiu J, Wang J, Tong C, Wang X, Miao J, Li Z, Li W, Yang J and Huang C: Histone-lysine N-methyltransferase SETD7 is a potential serum biomarker for colorectal cancer patients. EBioMedicine 37: 134-143, 2018.

16. Misra JR and Irvine KD: The Hippo signaling network and its biological functions. Annu Rev Genet 52: 65-87, 2018.

17. Azad T, Nouri K, Janse van Rensburg HJ, Maritan SM, Wu L, Hao Y, Montminy T, Yu J, Khanal P, Mulligan LM and Yang X: A gain-of-functional screen identifies the Hippo pathway as a central mediator of receptor tyrosine kinases during tumorigenesis. Oncogene 39: 334-355, 2020. 
18. Zhong W, Jiang H, Zou Y, Ren J, Li Z, He K, Zhao J, Zhou X, Mou D and Cai Y: The YAP signaling pathway promotes the progression of lymphatic malformations through the activation of lymphatic endothelial cells. Pediatr Res 89: 110-117, 2021.

19. Kovar H, Bierbaumer L and Radic-Sarikas B: The YAP/TAZ pathway in osteogenesis and bone sarcoma pathogenesis. Cells 9: 972, 2020.

20. Li H, Li X, Jing X, Li M, Ren Y, Chen J, Yang C, Wu H and Guo F: Hypoxia promotes maintenance of the chondrogenic phenotype in rat growth plate chondrocytes through the HIF-1 $\alpha$ / YAP signaling pathway. Int J Mol Med 42: 3181-3192, 2018.

21. Goto H, Nishio M, To Y, Oishi T, Miyachi Y, Maehama T, Nishina H, Akiyama H, Mak TW, Makii Y, et al: Loss of Mobla/b in mice results in chondrodysplasia due to YAP1/TAZ-TEADdependent repression of SOX9. Development 145: dev159244, 2018.

22. Hu S, Zhang C, Ni L, Huang C, Chen D, Shi K, Jin H, Zhang K, Li Y, Xie L, et al: Stabilization of HIF-1 $\alpha$ alleviates osteoarthritis via enhancing mitophagy. Cell Death Dis 11: 481, 2020.

23. Schipani E, Ryan HE, Didrickson S, Kobayashi T, Knight M and Johnson RS: Hypoxia in cartilage: HIF-1alpha is essential for chondrocyte growth arrest and survival. Genes Dev 15 2865-2876, 2001.

24. Stegen S, Laperre K, Eelen G, Rinaldi G, Fraisl P, Torrekens S, Van Looveren R, Loopmans S, Bultynck G, Vinckier S, et al: HIF-1 $\alpha$ metabolically controls collagen synthesis and modification in chondrocytes. Nature 565: 511-515, 2019.

25. Liu X, Chen Z, Xu C, Leng X, Cao H, Ouyang G and Xiao W: Repression of hypoxia-inducible factor $\alpha$ signaling by Set7-mediated methylation. Nucleic Acids Res 43: 5081-5098, 2015.

26. Oudhoff MJ, Freeman SA, Couzens AL, Antignano F, Kuznetsova E, Min PH, Northrop JP, Lehnertz B, BarsyteLovejoy D, Vedadi M, et al: Control of the hippo pathway by Set7-dependent methylation of Yap. Dev Cell 26: 188-194, 2013.

27. Zhang X, Li Y, Ma Y, Yang L, Wang T, Meng X, Zong Z, Sun X, Hua X and Li H: Yes-associated protein (YAP) binds to HIF-1a and sustains HIF-1 $\alpha$ protein stability to promote hepatocellular carcinoma cell glycolysis under hypoxic stress. J Exp Clin Cancer Res 37: 216, 2018.

28. Chen P, Vukicevic S, Sampath TK and Luyten FP: Bovine articular chondrocytes do not undergo hypertrophy when cultured in the presence of serum and osteogenic protein-1. Biochem Biophys Res Commun 197: 1253-1259, 1993.

29. Dasari VR, Mazack V, Feng W, Nash J, Carey DJ and Gogoi R: Verteporfin exhibits YAP-independent anti-proliferative and cytotoxic effects in endometrial cancer cells. Oncotarget 8 : 28628-28640, 2017.

30. Niu Y, Shi D, Li L, Guo J, Liu H and Yao X: Revealing inhibition difference between PFI-2 enantiomers against SETD7 by molecular dynamics simulations, binding free energy calculations and unbinding pathway analysis. Sci Rep 7: 46547, 2017.

31. Armiento AR, Stoddart MJ, Alini M and Eglin D: Biomaterials for articular cartilage tissue engineering: Learning from biology. Acta Biomater 65: 1-20, 2018.

32. Lafont JE: Lack of oxygen in articular cartilage: Consequences for chondrocyte biology. Int J Exp Pathol 91: 99-106, 2010.

33. Xue K, Zhang X, Gao Z, Xia W, Qi L and Liu K: Cartilage progenitor cells combined with PHBV in cartilage tissue engineering. J Transl Med 17: 104, 2019.
34. Wang H, Cao R, Xia L, Erdjument-Bromage H, Borchers C, Tempst $\mathrm{P}$ and Zhang Y: Purification and functional characterization of a histone H3-lysine 4-specific methyltransferase. Mol Cell 8: 1207-1217, 2001

35. Oudhoff MJ, Braam MJS, Freeman SA, Wong D, Rattray DG, Wang J, Antignano F, Snyder K, Refaeli I, Hughes MR, et al: SETD7 controls intestinal regeneration and tumorigenesis by regulating Wnt/ $\beta$-catenin and Hippo/YAP signaling. Dev Cell 37: 47-57, 2016

36. Gu Y, Wang X, Liu H, Li G, Yu W and Ma Q: SET7/9 promotes hepatocellular carcinoma progression through regulation of E2F1. Oncol Rep 40: 1863-1874, 2018.

37. Batista IAA and Helguero LA: Biological processes and signal transduction pathways regulated by the protein methyltransferase SETD7 and their significance in cancer. Signal Transduct Target Ther 3: 19, 2018

38. Pepe-Mooney BJ, Dill MT, Alemany A, Ordovas-Montanes J, Matsushita Y, Rao A, Sen A, Miyazaki M, Anakk S, Dawson PA, et al: Single-cell analysis of the liver epithelium reveals dynamic heterogeneity and an essential role for YAP in homeostasis and regeneration. Cell Stem Cell 25: 23-38.e8, 2019.

39. Chen J, You H, Li Y, Xu Y, He Q and Harris RC: EGF receptor-dependent YAP activation is important for renal recovery from AKI. J Am Soc Nephrol 29: 2372-2385, 2018.

40. Ma S, Meng Z, Chen R and Guan KL: The Hippo pathway: Biology and pathophysiology. Annu Rev Biochem 88: 577-604, 2019.

41. Oudhoff MJ, Antignano F, Chenery AL, Burrows K, Redpath SA Braam MJ, Perona-Wright $\mathrm{G}$ and Zaph C: Intestinal epithelial cell-intrinsic deletion of Setd7 identifies role for developmental pathways in immunity to helminth infection. PLoS Pathog 12: e1005876, 2016.

42. Semenza GL: Targeting HIF-1 for cancer therapy. Nat Rev Cancer 3: 721-732, 2003.

43. Lee JW, Bae SH, Jeong JW, Kim SH and Kim KW: Hypoxia-inducible factor (HIF-1)alpha: Its protein stability and biological functions. Exp Mol Med 36: 1-12, 2004.

44. Ke Q and Costa M: Hypoxia-inducible factor-1 (HIF-1). Mol Pharmacol 70: 1469-1480, 2006.

45. Xu G: HIF-1-mediated expression of Foxol serves an important role in the proliferation and apoptosis of osteoblasts derived from children's iliac cancellous bone. Mol Med Rep 17: 6621-6631, 2018.

46. Zhang C, Yang F, Cornelia R, Tang W, Swisher S and Kim H: Hypoxia-inducible factor-1 is a positive regulator of Sox 9 activity in femoral head osteonecrosis. Bone 48: 507-513, 2011.

47. Wu Y, Zou F, Lu Y, Li X, Li F, Feng X, Sun X and Liu Y: SETD7 promotes TNF- $\alpha$-induced proliferation and migration of airway smooth muscle cells in vitro through enhancing NF- $\mathrm{B} / \mathrm{CD} 38$ signaling. Int Immunopharmacol 72: 459-466, 2019.

48. Moya IM and Halder G: Hippo-YAP/TAZ signalling in organ regeneration and regenerative medicine. Nat Rev Mol Cell Biol 20: 211-226, 2019.

49. Soshnikova N: Functions of SETD7 during development, homeostasis and cancer. Stem Cell Investig 6: 26, 2019.

This work is licensed under a Creative Commons

Attribution-NonCommercial-NoDerivatives 4.0 International (CC BY-NC-ND 4.0) License. 